УДК 376.37

DOI 10.23951/2307-6127-2020-1-73-79

\title{
ОСОБЕННОСТИ ФОРМИРОВАНИЯ САМОСТОЯТЕЛЬНОГО ПОСТРОЕНИЯ РАССКАЗА У СТАРШИХ ДОШКОЛЬНИКОВ С НОРМОЙ И НАРУШЕНИЯМИ РЕЧЕВОГО РАЗВИТИЯ
}

\section{Н. А. Щербакова}

Воронежский государственный педагогический университет, Воронеж

Представлено исследование становления связной речи детей дошкольного возраста с нормой и нарушениями речевого развития. Проанализированы концепции ведущих отечественных ученых относительно изучения особенностей речевого развития у детей с общим недоразвитием речи. В рамках данной проблемы актуальным является рассмотрение вопросов формирования навыков самостоятельного построения рассказа у старших дошкольников с нормой и нарушениями речевого развития. Это связано с тем, что овладение рассказыванием представляет собой качественный переход на абсолютно новый уровень речемыслительной деятельности, что имеет значение в общем психическом развитии ребенка. Обосновывается мысль о том, что дошкольный возраст является благоприятным для интенсивного развития монологической речи, связного высказывания. Дошкольники в полной мере усваивают навыки владения семантическим, синтаксическим и морфологическим строем родного языка. Рассматриваются и обобщаются особенности речевого развития детей дошкольного возраста с общим недоразвитием речи. Приводятся эмпирические данные относительно ошибок в освоении детьми дошкольного возраста навыков самостоятельного построения рассказа. Достоверность результатов обоснована сравнительным анализом особенностей формирования построения рассказа детьми дошкольного возраста с общим недоразвитием речи и нормой речевого развития. С помощью сравнительного анализа выявляются словарные, грамматические, синтаксические затруднения детей дошкольного возраста в построении связного высказывания. Обосновывается необходимость разработки рекомендаций по коррекции особенностей самостоятельного составления рассказа у старших дошкольников с общим недоразвитием речи.

Ключевые слова: речевое развитие, самостоятельное рассказывание, психическое развитие ребенка дошкольного возраста, мышление, речь, воображение, память, речевые нарушения.

Федеральный государственный образовательный стандарт дошкольного образования (ФГОС) обеспечивает гармоничное и последовательное развитие личности, способствует развитию способностей детей в разных видах деятельности, в том числе и в речевой.

Особенности речевого развития у детей с общим недоразвитем речи (ОНР) представлены в научных трудах Р. И. Лалаевой [1], Т. Б. Филичевой [2], Г. В. Чиркиной [2], С. Н. Шаховской [3], которые проблему развития навыка составления самостоятельного рассказа старшими дошкольниками с ОНР рассматривают в рамках развития связной монологической речи.

Умение самостоятельно составлять рассказ, по мнению М. Ф. Фомичевой [4], определяет в речевом развитии ребенка качественный переход на новый уровень, связанный с развитием монологической речи. Данный уровень предоставляет дошкольнику возможность осуществить успешный переход к новому виду деятельности - учебной деятельности. В этом плане речемыслительной деятельности ребенок претерпевает скачок в своем развитии. 
В отечественной психологии и педагогике вопросы исследования связной речи, а именно самостоятельное построение рассказа, изучались в различных направлениях. Так, например, М. И. Львов разрабатывал методику обучения пересказу, О. С. Ушаковой рассматривались разнообразные аспекты развития связной речи.

Многие ученые, среди которых А. Н. Гвоздев, Г. А. Фомичева, В. К. Лоткарев, утверждают, что монологической речью ребенок овладевает уже в старшем дошкольном возрасте. Дошкольник может создать связное высказывание, способен пересказать увиденное или услышанное и построить собственный рассказ. Это возможно благодаря тому, что уже в пять-шесть лет дети в полной мере усваивают навыки владения морфологическим, семантическим, синтаксическим строем родного языка.

Следует отметить тот факт, что уже в старшем дошкольном возрасте дети могут выстроить внутренний план речевого высказывания, определить цель и выбрать необходимые языковые средства. Дошкольники могут безошибочно выявить семантическую или смысловую доминанту высказывания, представить свое повествование в форме логически законченной мысли. В этом случае их самостоятельное построение рассказа является законченным и логически выверенным. Рассказы детей могут быть своеобразными, самобытными, творчески оформленными.

Большая роль в построении рассказа отводится выбору дошкольниками выразительных языковых средств, дети могут легко дифференцировать их по способу употребления в определенной стилистике. Это обуславливает формирование умений и выработку навыка построения связного высказывания в целом. Кроме того, дети в старшем дошкольном возрасте уже могут отрефлексировать свой собственный речевой опыт и на этом основании оценить свой рассказ.

Рассматривая самостоятельное создание рассказа в рамках развития связной речи, необходимо отметить специфические черты его построения. Это прежде всего творческий характер рассказа. Рассказ должен быть построен не на основе трансляции образов и событий личного или читательского опыта ребенка, а создан посредством новых образов, ситуаций, действий или событий с выбором соответствующих языковых средств.

Начало исследования развития речи детей дошкольного возраста положено в работах Е. И. Тихеевой [5]. Автором была создана методика развития речи, в основе которой лежит идея учить дошкольников самостоятельно, творчески мыслить и последовательно выражать свои мысли. Одним из эффективных средств в этом направлении, по мнению автора, является творческое сочинение. Сочинение представляет собой логически законченное, завершенное по смыслу, систематизированное словесное изложение мысли, понятий.

Е. И. Тихеева [5] на основании экспериментальных исследований развития речи детей дошкольного возраста выделяет элементы и виды самостоятельного рассказа. Так, например, дети могут придумать начало и конец события, изображенного на картине; составить рассказ по плану; закончить рассказ, начатый воспитателем; составить рассказ по заглавию; составить рассказ по опорным словам.

Как считает Е. И. Тихеева, если проводить работу по развитию связной речи уже в младшем дошкольном возрасте, то можно добиться того, что дети уже в среднем дошкольном возрасте (к пяти годам) смогут самостоятельно составлять рассказ. Такая работа должна быть систематической и целенаправленной.

В целом работа по формированию умения самостоятельного составления рассказа проводится в течение всего дошкольного периода и носит системный характер. Такая работа должна быть зафиксирована относительно календарного и тематического планирования, 
выстроена методически грамотно, с соблюдением этапов от простого к сложному (самостоятельному творческому тексту).

Такая работа начинается с рассказа воспитателя, педагога об окружающем мире дошкольника. В качестве методического приема используется доступная детям педагогическая беседа на тему, предусмотренную программой ДОУ. Как правило, это темы «Фрукты», «Овощи», «Одежда», «Времена года», «Праздники» и т. п. В результате дети обогащают свой активный словарный запас, учатся пользоваться пассивным словарем, совершенствуют грамматику, участвуют в диалоге. Диалог дает возможность дошкольникам грамотно, четко и понятно строить высказывание, выражать свои мысли, замысел высказывания, для того чтобы собеседник понял смысл высказывания и нашел нужный ответ. Ребенок выбирает средства языка, планирует свое высказывание, учитывает индивидуальные возможности собеседника, его интересы и эмоциональное состояние.

Обучение диалогу является важным этапом речевого развития, после которого возможно самостоятельно строить отдельные высказывания, умозаключения и затем рассказ. На начальном этапе рассказ строится с опорой на наглядный материал, например детям демонстрируется картинка, и затем дается задание составить рассказ на заданную тему. Самым трудным для самостоятельного рассказывания считается рассказывание по воображению.

Таким образом, самостоятельное построение рассказа присуще детям старшего дошкольного возраста и связано с формированием у них связной речи, которая предполагает наличие активного и пассивного словаря ребенка, владение им языковыми средствами, выразительными средствами языка, способностью логически верно оформить речевое высказывание. Умение самостоятельно составлять рассказ формируется в среднем дошкольном возрасте и проходит систематически, целенаправленно и поэтапно от простой тематической беседы до составления высказывания по картине. В целом такая работа должна быть интересна для ребенка и отвечать его индивидуальным возрастным особенностям.

Нельзя не согласиться с мнением отечественных исследователей в области речевого развития ребенка Р. И. Лалаевой [1], Т. Б. Филичевой [2], Г. В. Чиркиной [2], С. Н. Шаховской [3] и ряда других в том, что развитие речи, являясь ведущим направлением дошкольного образования, определяет всестороннее развитие личности ребенка.

Однако наблюдается большая распространенность речевых нарушений, среди которых общее и тяжелое нарушения речи. Такие дети испытывают ряд трудностей при формировании связной речи, особенно при самостоятельном построении рассказа. В этом случае необходима логопедическая работа.

В системе коррекционных логопедических занятий большое место занимает работа по обучению рассказыванию, которая значимо отличается от принятой методической работы детского сада общего типа. Отличие состоит прежде всего в поэтапности отработки речевого материала. Помимо этого ведущую роль играет активизация словаря, при этом словарь должен опираться на речевой опыт ребенка и ранее быть изучен на занятиях, объединенных одной темой. Одну из ведущих ролей играет система наводящих вопросов. Благодаря этому дошкольник может привнести в рассказ более точные детали, дополнительную информацию. Дошкольник руководствуется воображением в самостоятельном составлении рассказов, а не образами по памяти, транслируя уже свершенные события, явления или образы. Задействование воображения в развитии связной речи - это более сложный процесс, чем трансляция по памяти, похожая на пересказ. Трудности возникают у всех детей дошкольного возраста, но особенно у дошкольников с общим недоразвитием речи. 
Дети дошкольного возраста с ОНР затрудняются в определении замысла рассказа, не могут выделить основную мысль из второстепенных. Дети часто сбиваются в восстановлении причинно-следственных связей в рассказе, таким образом, трудно определить сюжетную линию, зачастую ее просто нет. Дошкольники с ОНР, выполняя задание по составлению рассказа по картинке, сбиваются на пересказ текста, который был ранее очень хорошо им знаком.

Для выявления особенностей самостоятельного составления рассказа у старших дошкольников с нормой и нарушениями речевого развития было проведено эмпирическое исследование.

Для изучения уровня развития связной речи была применена методика балльной оценки В. П. Глухова [6].

Цель исследования - выявление особенностей самостоятельного составления рассказа детьми с OHP III-IV уровней.

В ходе применения данной методики были получены следующие результаты. У детей дошкольного возраста при составлении рассказа по картинке «Скажи, что здесь нарисовано» большее число затруднений вызвало смысловое согласование частей высказывания. Большинство детей с ОНР не могли активно использовать свой словарный запас, что ограничивает их возможности при составлении полноценного высказывания.

Например: «Кубики строит», «У мальчика лейка, льет на цветы», «Девочка вверх ловит, бабочка летит», «Она руки в стороны. Занимается спортом», «Кораблик плавает. Он его пускает».

Фразы детей с ОНР очень короткие, состоящие из двух, максимум трех слов. Предложения, как правило, простые, нераспространенные. Сложные синтаксические конструкции дети практически не употребляют в своей речи. Следовательно, их высказывания очень скудны и не имеют смысловой связи между собой. Дошкольники с ОНР часто пропускают слова, заменяя их звукоподражательными, неправильно употребляют глагольные формы, часто дублируют одни и те же части высказывания. Речь изобилует повторами. Встречаются ошибки, связанные со слабостью лексической дифференциации. Например, «Девочка грибы в лукошке. Пошла в лесу собирать грибы, ягоды. У нее корзинка грибы» (Маша К. ОНР).

Составляя самостоятельный рассказ по предложенному тексту, в роли которого выступали сказки, хорошо известные детям, дошкольники с ОНР испытывали затруднения в пересказе данного текста.

В целом для детей с ОНР характерны следующие затруднения в построении связного пересказа предложенного текста. Несмотря на то что сюжет сказки был им близок и знаком, не могли ее пересказать даже с помощью дополнительных вопросов. Затруднения возникали и при повторном чтении и разборе сказки. Дошкольники с ОНР не могли выстроить сюжетную линию, постоянно отвлекались на похожие ситуации из их личного или читательского опыта. Фразы были короткими, и зачастую дети отказывались продолжить повествование. Построенные предложения носили схематический характер и неоднократно повторялись в речи. События, описываемые детьми, не завершались и заменялись на длительные паузы, что отвлекало детей от работы над текстом. В результате дети с ОНР теряли нить повествования и не могли вспомнить и повторить выполняемое задание. Часто повествование из контекстного превращалось в ситуативное. Был нарушен порядок слов. Воспитанники в своих сообщениях часто застревают, акцентируют внимание на отдельных деталях, предметах, в результате теряется смысловая нить и логичность рассказа. Например, «Дед посадил репку. Выросла она. Стал дед тянуть. Не смог. Зовет бабку» (Катя К. ОНР). 
По полученным результатам самостоятельного построения рассказа детьми дошкольного возраста с нормой речевого развития можно сделать вывод о том, что дошкольники практически безошибочно справились с заданием. Их словарный запас довольно широкий и многообразный. Дети использовали, помимо имен существительных и глаголов, прилагательные. Тем самым могли выразить свое отношение к рассказу, его героям. Дети дошкольного возраста с нормой речевого развития соблюдали логику повествования, могли выделить основную мысль и сюжетную линию, определить замысел. Часто дети обращали внимание на мелкие детали и при построении рассказа использовали множество подробностей. Например, большое внимание дети уделяли внешнему виду героя, его настроению и т. п. Дети с нормальным речевым развитием более раскрепощены эмоционально и значительно легче излагают собственные суждения. Например, «Мальчик поливает красивые цветы из лейки», «Маленькая девочка ловит желтую бабочку сачком», «Мальчик играет разноцветными кубиками», «Девочка с удовольствием делает утреннюю зарядку», «Малыш запускает кораблик в речке» (Полина В. Норма речевого развития).

Характерным для детей с нормой речевого развития было то, что они привносили в сюжет многое из своего личного опыта. Достаточный словарный запас позволял детям в полной мере высказать свою мысль, выразить свое переживание, передать настроение героев. Например: «Девочка Маша пошла в лес за грибами. В лесу на полянке она увидела красивые и разные цветы и большие деревья. Там, наверное, были звери: ежики, зайчики. „Как весело и интересно собирать цветы!“ - подумала Маша» (Полина В. Норма речевого развития).

Однако дети с нормой речевого развития испытывали незначительные трудности при пересказе сказки. Так, например, некоторые дети не в полном объеме использовали лексику сказки, делали значительные паузы, подбирая слова и вспоминая логику сказки. Затруднялись выделить основную мысль сказки.

Дети с нормой речевого развития отличались умением ориентироваться на тему и использовать свои представления в развитии сюжета. Понимание задания дети демонстрировали на использовании лексики, указывающей на возможность случайного происшествия: «Как-то раз...», «Однажды...», «Это случилось...», «Один раз...», «Это было...».

В рассказах детей можно отметить как элементы фантазирования, так и умение использовать новые элементы в соответствии с сюжетной линией.

Таким образом, в результате исследования особенностей формирования самостоятельного построения рассказа детьми старшего дошкольного возраста можно заключить, что дети с ОНР имеют рад трудностей, связанных с логическим построением связного высказывания. Дети с общим недоразвитием речи создают содержательно бедные рассказы.

В детских рассказах не раскрывается тема, нет подбора выразительных средств языка. Налицо трудности владения словарным запасом слов. Он беден, как активный, так и пассивный. Эпизоды, описываемые детьми, не связаны между собой, допускаются паузы, ведущие к потере нити повествования. Детям с ОНР тяжело привлекать языковой материал из личного опыта, так как дети не могут вербально выразить и понять прочитанное им. Следовательно, детям тяжело привнести эмоциональную окраску в повествование, выразить настроение, часто дети прибегают к паралингвистическим средствам выражения (мимика, жесты и т. д.). Очевидную сложность представляли задания на составление рассказа по заданной теме. Дети терялись, не могли понять задание и пытались повторять за педагогом и друг за другом логику событий, части текста или характеристику героев. Труднее всего детям давалась диалоговая форма построения рассказа. 
Жизненный опыт детей с недоразвитием речи (негативный) снижает мотивацию на высказывания, импровизацию, и в этом случае педагог является моделью и поддержкой для развития творческих речевых и эмоциональных возможностей ребенка.

Несформированность самостоятельного рассказывания у детей с общим недоразвитием речи обусловлена трудностями преобразования полученного опыта. Неумение анализировать пережитый лично опыт, услышанный от других или полученный из книг, создает трудности создания нового явления: новый сюжет, новый облик героя, обстановку и т. д. У детей с общим недоразвитием речи налицо отставание в формировании всех компонентов самостоятельного рассказа.

\section{Список литературы}

1. Лалаева Р. И., Серебрякова Н. В. Коррекция общего недоразвития речи у дошкольников. СПб.: Каро, 2006. 160 с.

2. Филичева Т. Б., Чиркина Г. В. Устранение общего недоразвития речи у детей дошкольного возраста. М.: Айрис-Пресс: Айрис-Дидактика, 2015. 212 с.

3. Шаховская С. Н. Развитие словаря в системе работы при общем недоразвитии речи. М.: Эксмо, 2014. 450 с.

4. Фомичева М. Ф. Воспитание у детей правильного произношения. М.: Владос, 2005. 186 с.

5. Тихеева Е. И. Развитие речи детей (раннего и дошкольного возраста). М.: Слово, 2011. $411 \mathrm{c.}$

6. Глухов В. П. Особенности формирования связной монологической речи детей старшего дошкольного возраста с общим речевым недоразвитием: автореф. дис. ... канд. пед. наук. Л., 1987. 26 с.

Щербакова Наталья Александровна, кандидат психологических наук, доцент, Воронежский государственный педагогический университет (ул. Ленина, 86, Воронеж, Россия, 394024). E-mail: tyshonok@yandex.ru

Материал поступил в редакиию 26.09.2019.

DOI 10.23951/2307-6127-2020-1-73-79

\section{FEATURES OF FORMATION OF INDEPENDENT CONSTRUCTION OF A STORY IN SENIOR PRESCHOOL CHILDREN WITH NORMAL AND IMPAIRED SPEECH DEVELOPMENT}

\section{N. A. Shcherbakova}

\section{Voronezh State Pedagogical University, Voronezh, Russian Federation}

This article is devoted to the study of the formation of coherent speech of preschool children with normal and impaired speech development. The article analyzes the concept of the leading Russian scientists to study the features of speech development in children with general underdevelopment of speech. Within the framework of this problem, it is urgent to consider the issues of formation of an independent construction of a story in older preschoolers with the norm and disorders of speech development. This is due to the fact that the mastery of storytelling is a qualitative transition to a completely new level of verbal activity of a child, which is important in the overall mental development of a child. The idea that preschool age is favorable for intensive development of monological speech and coherent utterance is substantiated. Preschoolers fully learn the skills of semantic, syntactic and morphological structure of the native language. The article discusses and summarizes the features of speech development of preschool children with General underdevelopment of speech. The article presents empirical data on the errors in the development of independent storytelling in preschool children. The reliability of the results is substantiated by the comparative analysis of the peculiarities of formation of the plot of preschoolers with general underdevelopment of speech and normal speech development. On the basis of the comparative analysis, vocabulary, grammar and syntactic difficulties of preschool children in construction of the coherent 
statement are revealed. In conclusion, on the basis of the above conclusions, the need to develop recommendations for correcting the features of self-compilation of a story among older preschoolers with general underdevelopment of speech is justified.

Keywords: speech development, independent construction of a story, mental development of a preschool child, thinking, speech, imagination, memory, speech disorders.

\section{References}

1. Lalayeva R. I., Serebryakova N. V. Korrektsiya obshchego nedorazvitiya rechi u doshkol'nikov [Correction of general underdevelopment of speech in preschool children]. Saint Petersburg, Karo Publ., 2006. 160 p. (in Russian).

2. Filicheva T. B., Chirkina G. V. Ustraneniye obshchego nedorazvitiya rechi u detey doshkol'nogo vozrasta [The elimination of the general underdevelopment of speech in children of preschool age]. Moscow, Ayris-Press; Ayris-Didaktika Publ., 2015. 212 p. (in Russian).

3. Shakhovskaya S. N. Razvitiye slovarya $v$ sisteme raboty pri obshchem nedorazvitii rechi [Development of vocabulary in the system of work with general underdevelopment of speech]. Moscow, Eksmo Publ., 2014. 450 p. (in Russian).

4. Fomicheva M. F. Vospitaniye $u$ detey pravil'nogo proiznosheniya [Training in children correct pronunciation]. Moscow, Vlados Publ., 2005. 186 p. (in Russian).

5. Tikheyeva E. I. Razvitiye rechi detey (rannego i doshkol'nogo vozrasta) [Development of children's speech (early and preschool age)]. Moscow, Slovo Publ., 2011. 411 p. (in Russian).

6. Glukhov V. P. Osobennosti formirovaniya svyaznoy monologicheskoy rechi detey starshego doshkol'nogo vozrasta s obshchim rechevym nedorazvitiyem [Features of formation of coherent monologic speech of children of senior preschool age with the General speech underdevelopment]. Leningrad, 1987. 26 p. (in Russia).

Shcherbakova N. A., Voronezh State Pedagogical University (ul. Lenina, 86, Voronezh, Russian Federation, 394024). E-mail: tyshonok@yandex.ru 